\title{
A systematic review highlights the need to improve the quality and applicability of trials of physical therapy interventions for low back pain
}

Aidan G Cashin ${ }^{1,2}$, Hopin Lee ${ }^{3,4}$, Matthew K Bagg ${ }^{1,2,5}$, Edel O’Hagan ${ }^{1,2}$, Adrian C Traeger ${ }^{6}$, Steven J Kamper $^{6,7}$, Thiago Folly ${ }^{1}$, Matthew D Jones ${ }^{1,8}$, John Booth ${ }^{8}$, James H McAuley ${ }^{1,8}$

${ }^{1}$ Neuroscience Research Australia, Sydney, Australia

${ }^{2}$ Prince of Wales Clinical School, Faculty of Medicine, University of New South Wales, Sydney, Australia ${ }^{3}$ Centre for Statistics in Medicine \& Rehabilitation Research in Oxford, Nuffield Department of Orthopaedics Rheumatology and Musculoskeletal Sciences (NDORMS), University of Oxford, UK

${ }^{4}$ School of Medicine and Public Health, University of Newcastle, Newcastle, Australia

${ }^{5}$ New College Village, University of New South Wales, Sydney, Australia

${ }^{6}$ Institute for Musculoskeletal Health, Faculty of Medicine and Health, University of Sydney, Australia

${ }^{7}$ Centre for Pain, Health and Lifestyle, Australia

${ }^{8}$ School of Medical Sciences, Faculty of Medicine, University of New South Wales, Sydney, Australia

\section{Corresponding author:}

Dr Hopin Lee

Botnar Research Centre

Nuffield Department of Orthopaedics Rheumatology and Musculoskeletal Sciences, University of Oxford, Windmill Road, Headington, Oxford, UK OX3 7LD

Tel: +44018 65226493

Email: hopin.lee@ndorms.ox.ac.uk

Tables: $\quad 1$

Figures: $\quad 7$

Appendix: $\quad 3$ (PRISMA checklist, search strategy, data extraction guidance document) 


\section{ABSTRACT}

\section{Objective}

To review and assess the methodological quality of randomised controlled trials that test physical therapy interventions for low back pain.

\section{Study Design and Setting}

Systematic review of trials of physical therapy interventions to prevent or treat low back pain (of any duration or type) in participants of any age indexed on the Physiotherapy Evidence Database (PEDro). Existing PEDro scale ratings were used to evaluate methodology quality.

\section{Results}

This review identified 2215 trials. The majority of trials were for adults ( $\mathrm{n}=2136,96.4 \%)$, low back pain without specific aetiology $(\mathrm{n}=1863,84.1 \%)$, and chronic duration $(\mathrm{n}=947,42.8 \%)$. The quality of trials improved over time, however most were at risk of bias. Less than half of the trials concealed allocation to intervention $(n=813,36.7 \%)$, used intention-to-treat principles $(n=778,35.1 \%)$, blinded assessors $(n=810,36.6 \%)$, participants $(n=174,7.9 \%)$ and therapists $(n=39,1.8 \%)$. These findings did not vary by type of therapy.

\section{Conclusion}

The majority of trials that test physical therapy interventions for low back pain have methodological limitations that could bias treatment effect estimates. Greater attention to simple methodological features, such as allocation concealment and the reporting of intention-to-treat effects, would improve the quality of trials testing physical therapy interventions for low back pain.

Key words: $\quad$ low back pain; non-pharmacological; physical therapy; quality; bias; evidence-based medicine

Running title: $\quad$ Quality of physical therapy intervention trials for low back pain

Word Count: $\quad 189$ words (Abstract)

2139 words (Introduction, Method, Results, Discussion, Conclusion) 


\section{Introduction}

Low back pain is a global health problem [1-3]. It is the leading cause of years lost to disability worldwide [4]. In 2013 in the USA, low back pain accounted for approximately $\$ 87.6$ billion USD ( $\$ 67.5$ billion-\$94.1 billion) in personal healthcare spending [5]. The costs attributed to the management of low back pain are rising faster than for any other health condition [5].

Most international clinical practice guidelines recommend that first-line care for low back pain should involve non-pharmacological interventions [6]. The most common non-pharmacological interventions include those provided by physical therapists such as exercise, manual therapy, education and acupuncture. The volume of evidence for physical therapy interventions for low back pain has increased over time. This is partly reflected by the increasing number of randomised controlled trials (RCTs) in the field [7-9]. However, it is unclear whether their methodological quality is also improving [9-11]. Given the nature of physical therapy interventions, it can be difficult to achieve adequate adherence to allocated interventions, and to blind participants and therapists. These challenges introduce the potential for risk of bias in RCTs of physical therapies. The primary aim of this study was to review and assess the methodological quality of RCTs of physical therapy interventions for low back pain.

\section{Methods}

We conducted a systematic review of RCTs of physical therapy interventions for low back pain. We preregistered the protocol prior to data extraction on the $11^{\text {th }}$ July 2018 on the Open Science Framework, (https://osf.io/pdmgx/). This study is reported in accordance to the Preferred Reporting Items for Systematic reviews and Meta-Analyses (PRISMA) guideline [12], (appendix file A1).

\subsection{Data sources and Searches}

We searched the Physiotherapy Evidence Database (PEDro) (www.pedro.org.au) to obtain reports of RCTs of physical therapy interventions for low back pain from inception to the $1^{\text {st }}$ July 2019 . The search strategy was developed in collaboration with a member of the PEDro steering committee using a combination of PEDro codes (https://www.pedro.org.au/english/downloads/codes/) and the term 'low back pain'. We used a sensitive search strategy as we wanted to identify all RCTs indexed on PEDro related to low back pain. The complete search strategy is described in the appendix file A2.

PEDro is considered the most comprehensive electronic bibliographic database of RCTs of all interventions that are, or could be, provided by physical therapists, indexing up to $99 \%$ of relevant RCTs [13-15]. To ensure all RCTs of physical therapy interventions are indexed, PEDro employs 
broad inclusion criteria, indexing RCTs from multiple interdisciplinary and RCT specific databases including Medline, Embase, CINAHL, AMED, PsycINFO and CENTRAL (for detailed methodology see https://www.pedro.org.au/english/faq/\#question_one). Essentially, PEDro includes trials of any intervention that is or could be within the scope of practice for physical therapists worldwide, such as active (exercise, skill training, respiratory interventions), passive (manual therapy, acupuncture, electrotherapies), education (information, reassurance, psychoeducation), health promotion (physical activity, healthy lifestyle) and ergonomic (orthosis and splints) interventions. PEDro is very highlyaccessed by a global audience; in 2019, PEDro was searched on average, every 10 seconds from 216 countries.

A key feature of PEDro is a report of the methodological quality, described as the PEDro scale, for each indexed RCT [15-17]. Eleven items are used to appraise external validity (item 1), internal validity (items 2-9) and statistical reporting (items 10-11) [18]. Items 2 to 11 can be summed to provide a score out of 10 , higher scores reflecting increased methodological quality $[15,16]$. The items have high interrater reliability and the total score is associated with other methodological quality tools such as the Jadad scale [19], and Cochrane Back and Neck Group risk of bias tool [20]. The PEDro quality items are increasingly being used to appraise RCTs beyond physical therapies, including broader health and medical research $[17,18]$.

This review focused on PEDro due to its comprehensive indexing of physical therapy related $\operatorname{RCTs}[13,14]$ and quality assessment using relevant, valid and reliable study quality items [18].

\subsection{Study Selection}

We included all RCTs indexed on PEDro that evaluated interventions aimed to prevent or treat low back pain. We included low back pain of any duration or type, as well as studies of mixed samples that included people with low back pain and other conditions (e.g., participants with either neck or low back pain). We excluded non-English language RCTs when it was not possible to determine eligibility for this review due to the absence of either an abstract or full text for translation.

Two reviewers independently screened all identified records. Eight reviewers, working in duplicate, independently evaluated the titles and abstracts of all identified records against the inclusion criteria. The full text of the record was retrieved when insufficient information was provided in the title and abstract to decide on inclusion. Disagreements were resolved by discussion, or through consensus with a third reviewer.

\subsection{Data extraction and Quality Assessment}


A custom datasheet for extraction was developed and pilot tested over 5 iterations, each using 20 RCTs. We extracted information to describe the study design, population characteristics, therapy type and methodological quality. First, we extracted study metadata from the PEDro database: study year, study participant age (coded as paediatric $<18 \mathrm{yrs}$; adult $18-70 \mathrm{yrs}$; geriatric $>70 \mathrm{yrs}$ ); therapy categories ('acupuncture'; 'behaviour modification'; 'education'; 'electrotherapies, heat, cold'; 'fitness training'; 'health promotion'; 'hydrotherapy, balneotherapy'; 'neurodevelopmental therapy, neurofacilitation'; 'orthoses, taping, splinting'; 'respiratory therapy'; 'skill training'; 'strength training'; 'manual therapy' [further coded as stretching, mobilisation, manipulation, massage]; 'no appropriate value in this field'), and individual item score for each of the 11 PEDro items. Description of the PEDro database codes can be found at https://www.pedro.org.au/english/downloads/codes/.

Secondly, we extracted additional information from each record: research question (coded as efficacy; effectiveness; economic evaluation; implementation/translation; unclear), intervention aim (prevention; treatment; combination), low back pain duration (acute $<6$ weeks; sub-acute $6-12$ weeks; chronic >12 weeks; mixed-duration; not reported) and low back pain classification (nonspecific; infection; fracture; inflammatory; radiculopathy; cancer; pregnancy; osteoporosis; mixed diagnosis; other). To ensure consistency between reviewers, a guidance document was (appendix file A3) used by all reviewers.

Two reviewers independently extracted data from included studies onto the custom extraction datasheet. Disagreements between reviewers were resolved through discussion, or through consulting a third reviewer.

We used the PEDro scale to appraise methodological quality. As recommended, we considered items 2-11 on the PEDro scale as the criteria for methodological quality in this study $[15,16]$. We used the ratings available for each indexed trial on PEDro for both English and non-English language trials. In brief, PEDro scale ratings are conducted independently and in duplicate by trained and experienced PEDro raters (see https://www.pedro.org.au/english/faq/\#question_five), with conflicts resolved by a third independent rater.

\subsection{Data Synthesis and Analysis}

We summarised the extracted data in tables, charts and figures. Categorical variables describing the scope of the evidence and satisfaction of the PEDro scale items were summarised using frequencies and percentages. Continuous variables describing the quality of trials were summarised using the mean, median, standard deviation and interquartile range. All data were analysed in R (Version 3.4.0) [21]. 


\section{Results}

\subsection{Study selection}

Our search identified 2846 RCTs (Figure 1). 539 RCTs were excluded following title and abstract screening; 2 non-English RCTs could not be translated to determine if inclusion criteria were satisfied and 537 RCTs did not include interventions designed to prevent or treat low back pain. Of the remaining 2307 eligible RCTs, we further excluded 47 RCTs published in 2019 to ensure complete data for each year, and 45 RCTs that were not officially rated by PEDro for methodological quality. Finally, we included 2215 RCTs in this study (Figure 1).

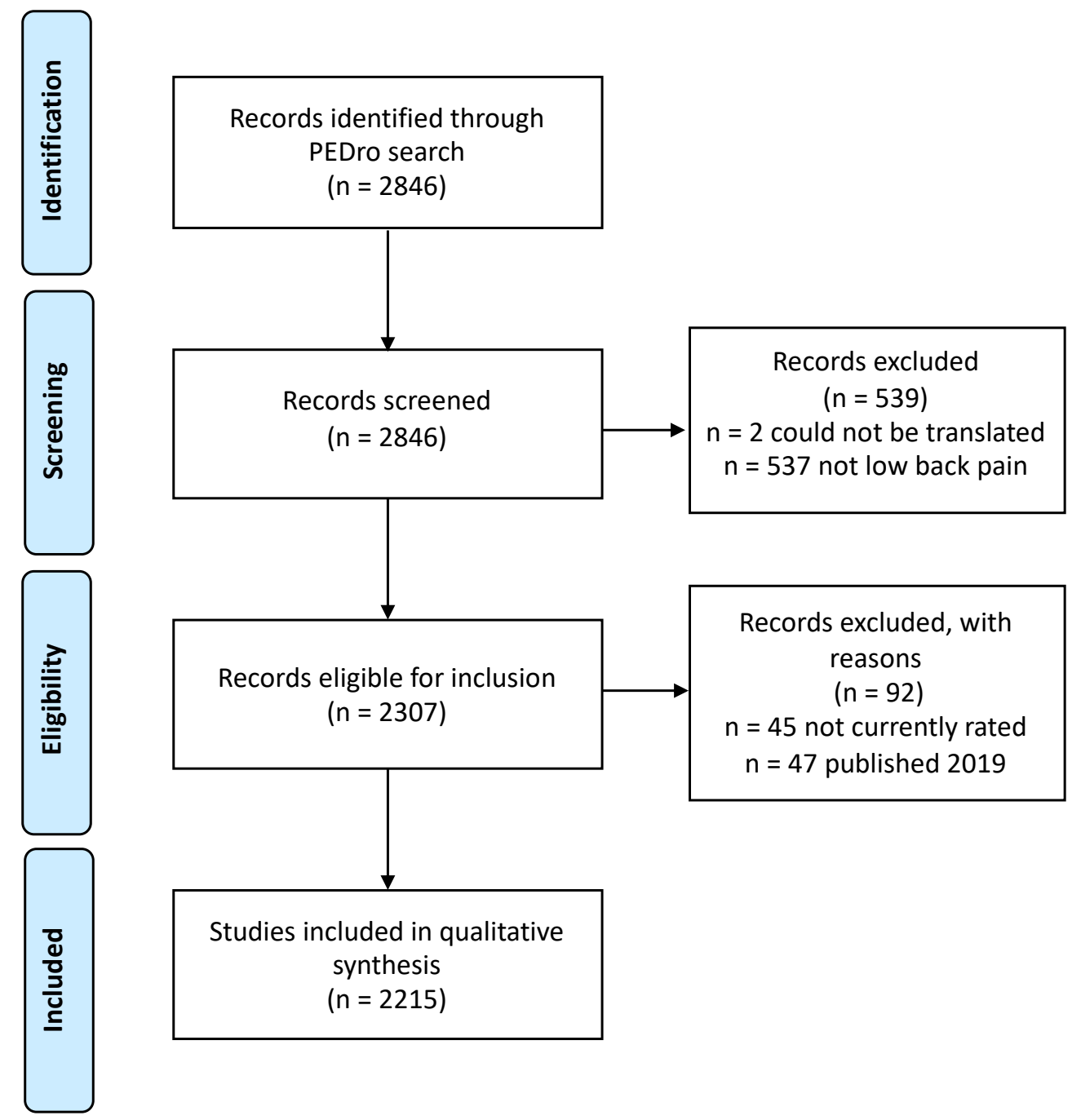

Figure 1. Prisma Flow Diagram 


\subsection{Physical therapy interventions for low back pain}

\subsubsection{Scope of the evidence}

Most commonly, RCTs were conducted in adults aged $18-65$ years $(n=2136,96.4 \%)$, people who had chronic low back pain ( $\mathrm{n}=947,42.8 \%)$ and people who had non-specific low back pain $(\mathrm{n}=1863$, 84.1\%). Fewer RCTs were conducted in paediatric $(n=20,0.9 \%)$ and geriatric populations $(n=59$, $2.7 \%)$, or for people with acute symptoms $(n=158,7.1 \%)$ or a specific diagnosis $(n=352,15.9 \%)$. Very few RCTs evaluated interventions designed to prevent low back pain $(n=50,2.3 \%)$ or to implement research findings $(n=9,0.4 \%)-$ Table 1 . 
Table 1. Scope of physical therapy evidence for low back pain in PEDro

\begin{tabular}{|c|c|}
\hline Characteristic & Total RCTs N(\%) \\
\hline Publications & 2215 \\
\hline \multicolumn{2}{|l|}{ Low Back Pain Diagnosis* } \\
\hline Nonspecific & $1863(84.1 \%)$ \\
\hline Radiculopathy & $120(5.4 \%)$ \\
\hline Pregnancy & $69(3.1 \%)$ \\
\hline Inflammatory & $62(2.8 \%)$ \\
\hline Fracture & $28(1.3 \%)$ \\
\hline Spinal Stenosis & $27(1.2 \%)$ \\
\hline Other & $16(0.7 \%)$ \\
\hline Mixed ( $\geq 2$ Types) & $15(0.7 \%)$ \\
\hline Osteoporosis & $12(0.5 \%)$ \\
\hline Cancer & $2(0.1 \%)$ \\
\hline \multicolumn{2}{|l|}{ Low Back Pain Duration* } \\
\hline Chronic & $947(42.8 \%)$ \\
\hline Not Reported & $878(39.6 \%)$ \\
\hline Mixed & $192(8.7 \%)$ \\
\hline Acute & $158(7.1 \%)$ \\
\hline Subacute & $40(1.8 \%)$ \\
\hline \multicolumn{2}{|l|}{ Age Group } \\
\hline Adult & $2136(96.4 \%)$ \\
\hline Geriatric & $59(2.7 \%)$ \\
\hline Paediatric & $20(0.9 \%)$ \\
\hline \multicolumn{2}{|l|}{ Research Question* } \\
\hline Effectiveness & $1395(63.0 \%)$ \\
\hline Efficacy & $417(18.8 \%)$ \\
\hline Efficacy / Effectiveness & $349(15.8 \%)$ \\
\hline Economic & $45(2.0 \%)$ \\
\hline Implementation & $9(0.4 \%)$ \\
\hline \multicolumn{2}{|l|}{ Research Type* } \\
\hline Treatment & $2140(96.6 \%)$ \\
\hline Prevention & $50(2.3 \%)$ \\
\hline Treat / Prevent & $25(1.1 \%)$ \\
\hline \multicolumn{2}{|l|}{ Therapy } \\
\hline $\begin{array}{l}\text { Manual Therapy (stretching, mobilisation, } \\
\text { manipulation, massage) }\end{array}$ & $933(42.1 \%)$ \\
\hline Strength Training & $651(29.4 \%)$ \\
\hline Education & $499(22.5 \%)$ \\
\hline Electrotherapies, Heat, Cold & $417(18.8 \%)$ \\
\hline Skill Training & $319(14.4 \%)$ \\
\hline Behaviour Modification & $306(13.8 \%)$ \\
\hline Acupuncture & $283(12.8 \%)$ \\
\hline Fitness Training & $271(12.2 \%)$ \\
\hline Orthoses, Taping, Splinting & $92(4.2 \%)$ \\
\hline Hydrotherapy, Balneotherapy & $69(3.1 \%)$ \\
\hline
\end{tabular}




\begin{tabular}{|l|l|} 
Health Promotion & $42(1.9 \%)$ \\
Neurodevelopmental Therapy, Neurofacilitation & $7(0.3 \%)$ \\
Respiratory Training & $5(0.2 \%)$ \\
Other & $91(4.1 \%)$ \\
Language & $1930(87.1 \%)$ \\
\hline English & $158(7.1 \%)$ \\
Chinese & $46(2.1 \%)$ \\
German & $15(0.7 \%)$ \\
Dutch & $15(0.7 \%)$ \\
French & $12(0.5 \%)$ \\
Japanese & $9(0.4 \%)$ \\
Portuguese & $8(0.4 \%)$ \\
Spanish & $7(0.3 \%)$ \\
Turkish & $6(0.3 \%)$ \\
Italian & $4(0.2 \%)$ \\
Korean & $3(0.1 \%)$ \\
Norwegian & $1(0.0 \%)$ \\
Danish & $1(0.0 \%)$ \\
Russian & \\
* The classification of each characteristic is described in the guidance document & $(\mathrm{appendix} \mathrm{file} \mathrm{A3).}$
\end{tabular}

\subsubsection{Volume of RCTs}

The largest increase in the absolute number of RCTs published per year was observed between 1998 to 2018, (36 in 1998 vs 133 in 2018). The growth in published RCTs over this 20 -year period was $269 \%$; an increase of $9 \%$ per year (Figure 2). The top three most investigated interventions were manual therapy $(\mathrm{n}=933,42.1 \%)$, strength training $(\mathrm{n}=651,29.4 \%)$ and education $(\mathrm{n}=499,22.5 \%)$.

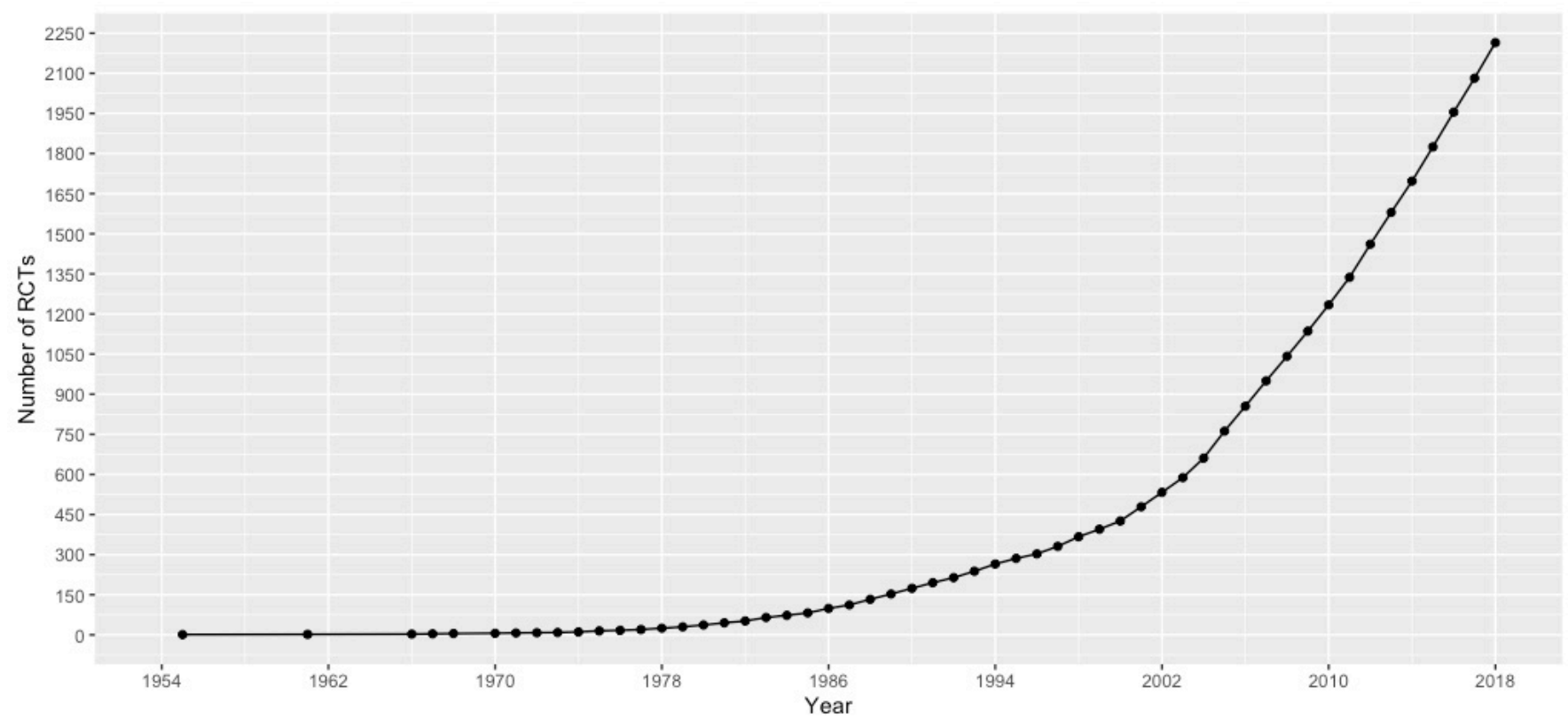

Figure 2. Cumulative plot of the number of published RCTs between 1955 to 2018 .

Quality of physical therapy intervention trials for low back pain

Cashin et al. (2020) 


\subsection{Quality of randomised controlled trials}

The mean number of methodological quality items on the PEDro scale satisfied by all published RCTs was 5.4 (SD \pm 1.6 ) out of 10 items (Figure 3 ). The mean number of items satisfied improved from 2.0 in 1955 to 6.0 in 2018, and this trend plateaued over the last decade from 2018 (Figure 4).

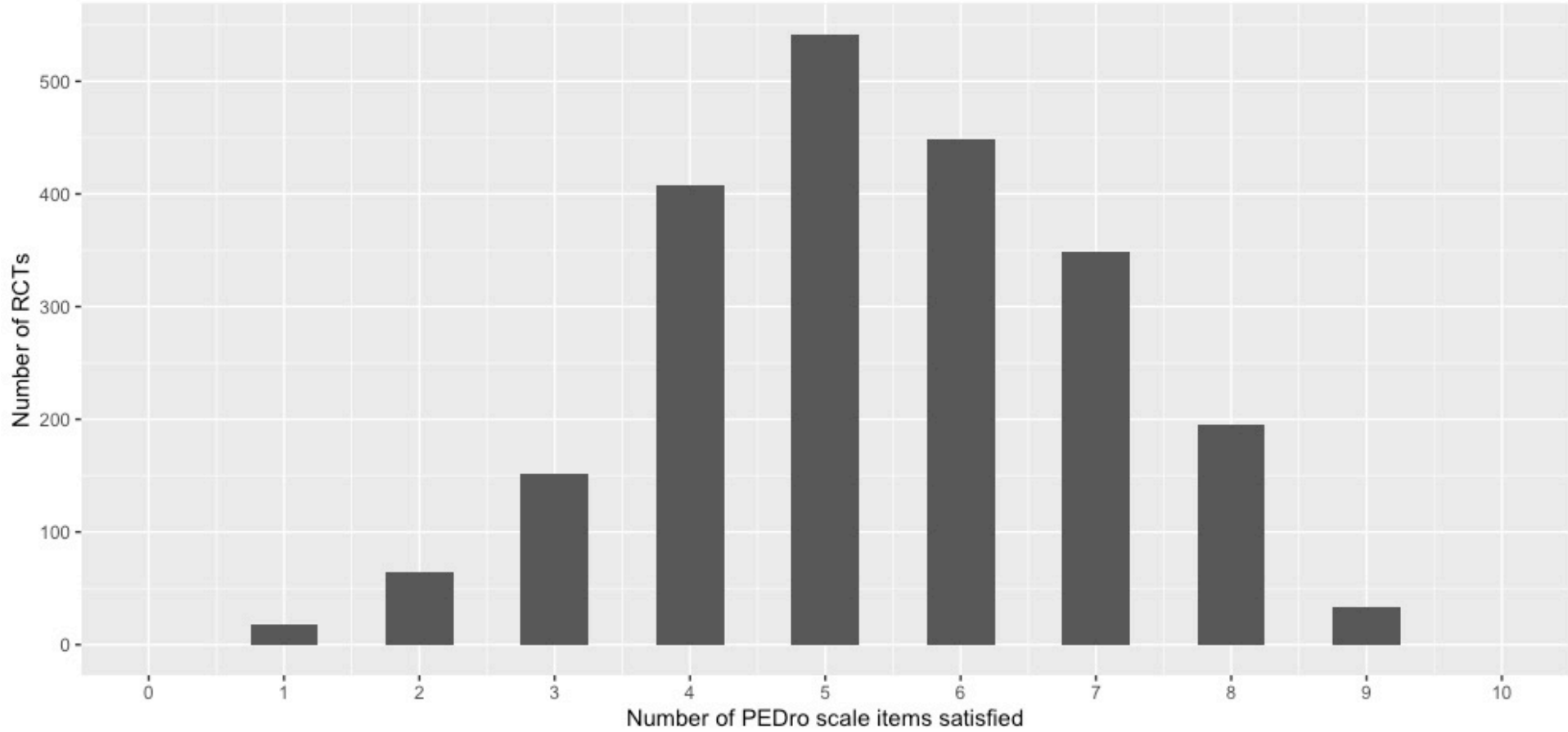

Figure 3. Frequency distribution of the total number of PEDro scale items satisfied by all RCTs.

Satisfaction of more PEDro items reflects increased methodological quality.

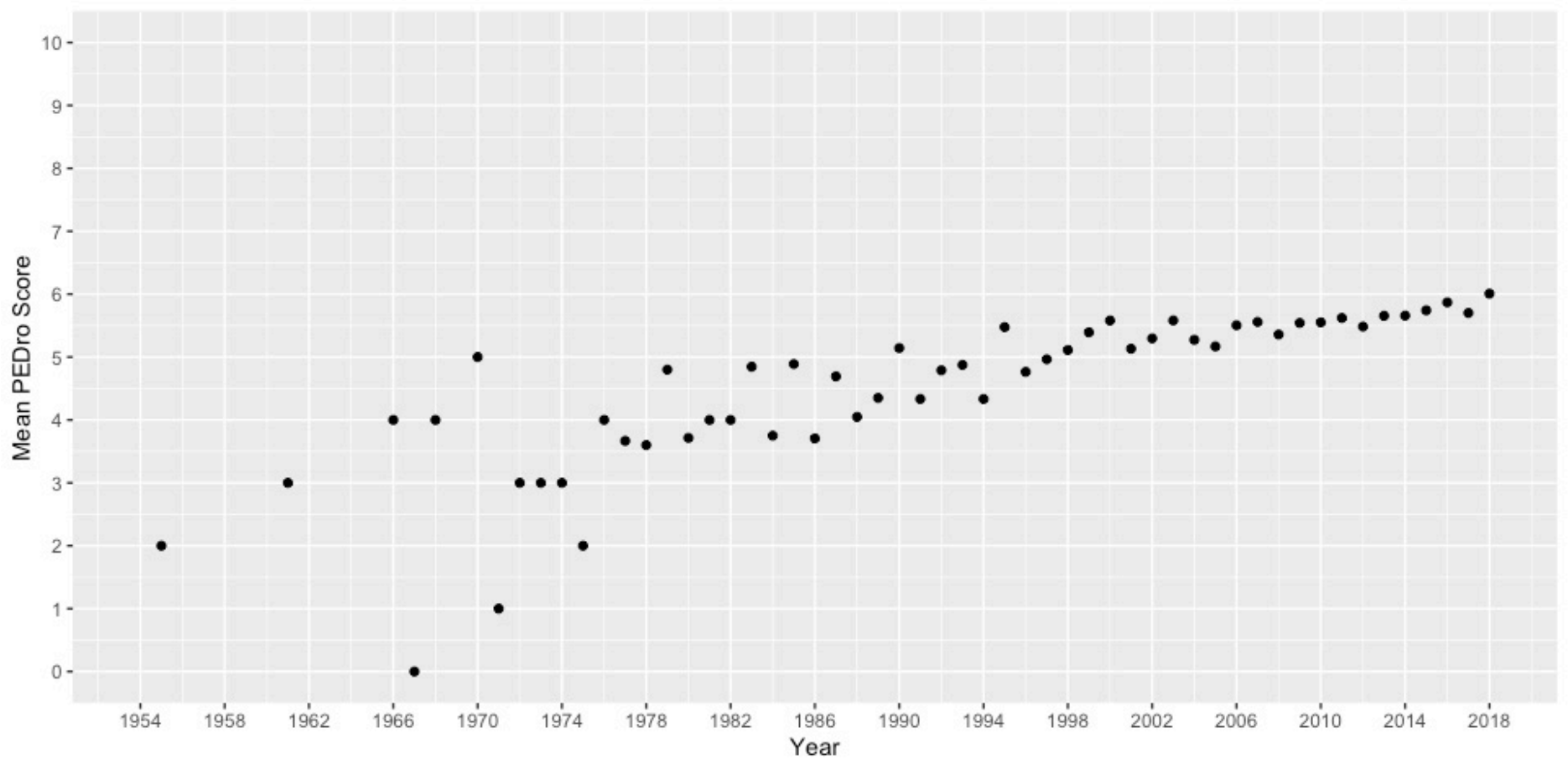

Figure 4. Annual trend in the mean number of PEDro scale items satisfied by all RCTs

Quality of physical therapy intervention trials for low back pain

Cashin et al. (2020) 
The proportion of RCTs that satisfied each of the methodological quality items of the PEDro scale is provided in Figure 5. Most RCTs reported between group comparisons $(\mathrm{n}=2084,94.1 \%)$ and point estimates and a measure of variability $(n=2025,91.4 \%)$. Less than half of the trials concealed allocation to intervention $(n=813,36.7 \%)$, used and reported intention-to-treat effects $(n=778,35.1 \%)$, blinded assessors $(n=810,36.6 \%)$, participants $(n=174,7.9 \%)$ and therapists $(n=39,1.8 \%)$.

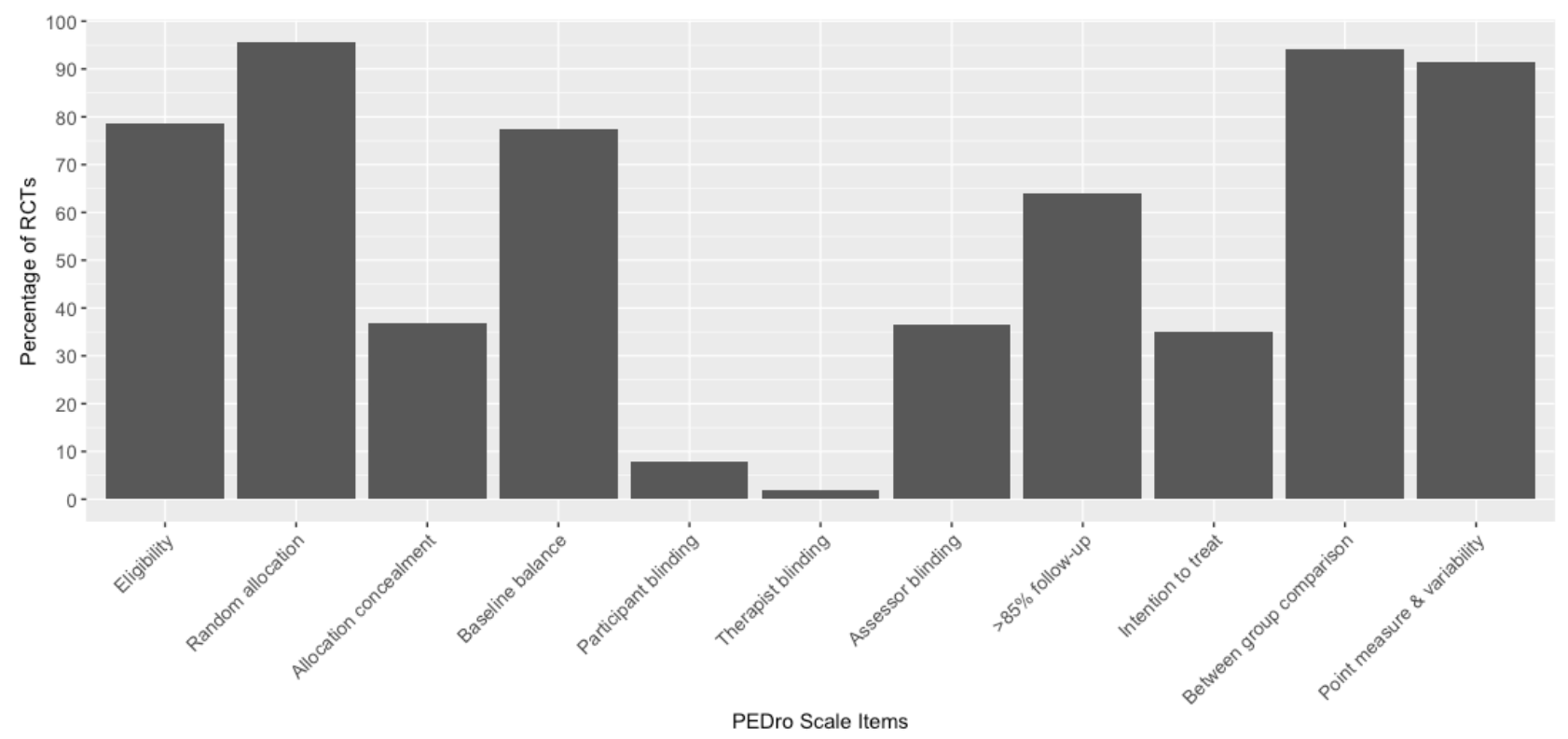

Figure 5. Percentage of RCTs $(n=2215)$ that satisfied each item of the PEDro scale.

When stratified by therapy, allocation concealment, reporting of intention-to-treat analyses and blinding of assessor, participant and therapist were consistently the least satisfied items (Figure 6). The proportion of RCTs satisfying each item on the PEDro scale has increased over time, although the rates of increase appear to have slowed in the last decade (Figure 7).

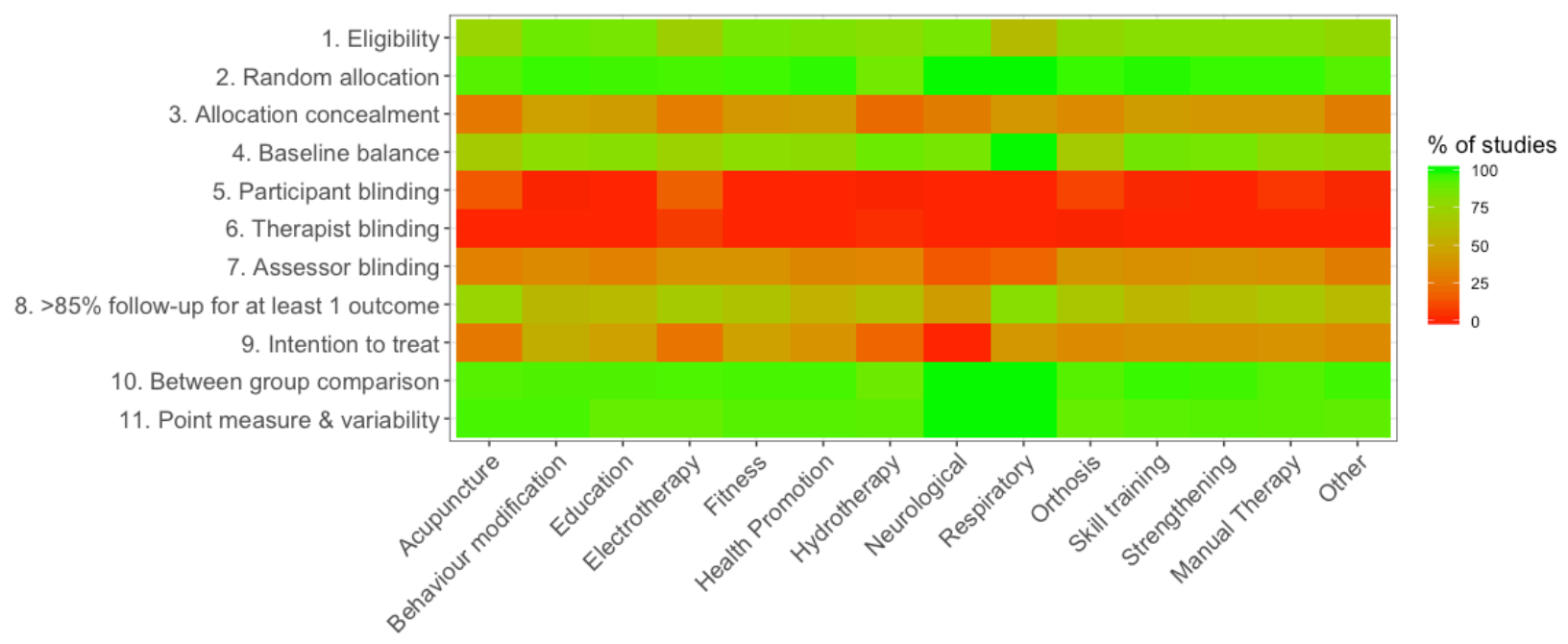

Figure 6. Percentage of all included RCTs that satisfied each item of the PEDro scale, stratified by type of therapy. 

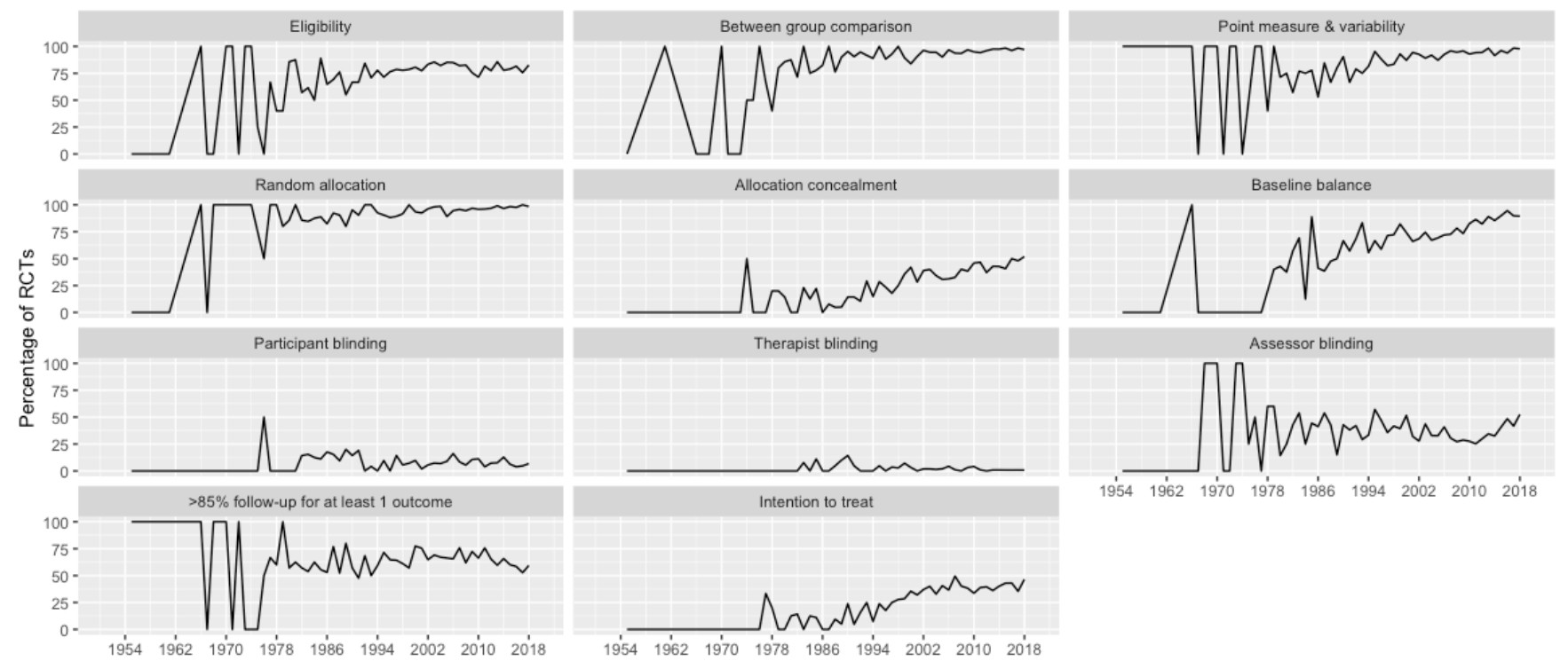

Figure 7. Trends in the number of RCTs satisfying each PEDro Scale Item over time

\section{Discussion}

To our knowledge, this review presents the most comprehensive appraisal of RCTs of physical therapy interventions for low back pain. Our findings showed that the majority of RCTs have methodological limitations that could bias treatment effect estimates. Although the quality of RCTs has improved, fundamental and straightforward methodological practices such as allocation concealment and analyses using intention-to-treat principles are not commonly utilised. There are also major gaps in the scope of the evidence-base for relevant populations and therapies, particularly for children and older people. Greater attention in the design of RCTs is needed to improve the evidence for the efficacy and effectiveness of physical therapy interventions for low back pain.

The lack of allocation concealment, blinding and intention to treat analyses has also been reported in previous systematic reviews of low back pain RCTs [9-11]. Our analysis shows that the adoption of allocation concealment and intention-to-treat analysis is improving in low back pain RCTs. This could reflect a greater adoption of these practices in RCTs and/or improved reporting following the introduction of reporting guidelines such as the Consolidated Standards of Reporting Trials (CONSORT)[22] and the relevant extension for non-pharmacological treatments [23]. However, reports of blinding of participants, therapists and assessors have not improved. The difficulties of blinding participants, therapists, and at times, assessors in RCTs of physical therapy interventions has been acknowledged [24-26]. However, allocation concealment and reporting of intention-to-treat effects are usually straightforward and could be easily implemented [24,25,27]. 
Methodological investigations, including meta-epidemiological studies have provided some insight into the biasing effects of methodological features on treatment effect estimates in RCTs [28-31]. Although the magnitude and direction of bias has been shown to vary [31,32], the influence of unclear or inadequate allocation concealment and lack of blinding are likely greatest when outcome measures are subjective $[29,33]$ - for example self-reported ratings of pain intensity and physical functioning common to low back pain research. This review shows that methodological limitations that can introduce bias are common in low back pain RCTs. Research that is at high risk of bias is problematic and can lead to misleading results in randomised controlled trials and in the systematic reviews that include them $[30,34]$ producing potentially erroneous conclusions with adverse consequences for patients and policy [35].

Some have questioned the need for allocation concealment and intention-to-treat analysis to protect against bias in low back pain RCTs [36]. In addition, the recent MetaBLIND study found no difference in average treatment effects between RCTs that masked participants, healthcare providers and outcome assessors versus studies that did not mask [37]. These findings must be interpreted with caution. It is possible that these crude associations between methodological techniques and bias reflect limitations in the meta-epidemiological approaches used, such as confounding bias [37]. There may be common causes (confounders) of the methodological technique and the trial outcome which could bias the true causal effect of techniques such as blinding [38]. Replication studies that use a causal inference approach to mitigate confounding bias in meta-epidemiological studies are needed before recalling important methodological safeguards in trials.

Blinding participants and therapists in RCTs of physical therapy interventions is difficult, and at times, can be impossible to establish and/or to maintain [24,39,40]. These difficulties partly reflect the challenge of developing and delivering indistinguishable sham control interventions [40,41]. There are a several examples where trialists have devised creative and convincing sham control interventions, for example; in acupuncture [42], electrophysical[43], educational[44], spinal manipulative therapy[45,46] and exercise[47] interventions. The blinding of outcome assessors is comparatively more straightforward [24], but in some situations, still may not be feasible due to increased logistical demands and persisting risk of unblinding. Although not assessed in this review, blinding of the data analyst is an additional practice which can be more easily implemented to minimise the risk of bias $[48,49]$.

The importance of blinding in physical therapy RCTs may become less relevant if replications of the the MetaBLIND study show that blinding does not have a causal effect on treatment effects [38]. Although such findings could remove blinding from quality appraisal tools, there is insufficient 
evidence to support this. The removal of blinding could improve the apparent quality of nonpharmacological trials including those relevant to physical therapy.

Although the evidence-base for physical therapy interventions is growing, and abundant in some areas, this review shows that there remains substantial gaps. Low back pain affects people across the lifespan $[1,50,51]$, yet there are comparatively few published RCTs in children or adolescents $(n=20)$ and older adults $(n=59)$. There is also little research aimed to prevent the onset of low back pain in asymptomatic individuals $(\mathrm{n}=50)$ and preventing progression to chronic symptoms in people with acute $(n=158)$ and sub-acute $(n=40)$ low back pain. Very few RCTs focused on interventions to implement research findings $(n=9)$, which may contribute to the observed evidence-practice gap [3].

Our review has some limitations. We relied on the reporting of study methods to assess methodological quality, rather than assessing the conduct of the study itself. Although all available methodological quality assessment tools share this problem, we were unable to examine the impact of poor reporting from the included RCTs on the PEDro scale rating. Secondly, the choice of tool and method used for appraising the quality of RCTs is likely to influence the rating of methodological quality. We chose the PEDro scale, a tool specifically developed for physical therapy interventions with acceptable measurement properties [18]. Finally, our review focused on one database - PEDro. We chose PEDro because it is the most comprehensive bibliographic databases of RCTs of physical therapy interventions, indexing up to $99 \%$ of relevant studies [13,14]. Despite this, we acknowledge that some trials of physical therapy interventions for low back pain may have been missed.

\section{Conclusion}

The majority of RCT evidence of physical therapy interventions for low back pain is at risk of bias. Although quality is improving on average, fundamental but simple to implement methodological features such as concealment of allocation and reporting intention-to-treat effects are not commonly applied. The number of published RCTs relevant to low back pain has dramatically increased over time. Trials most commonly test exercise, education, and manual therapy interventions in adults with chronic, non-specific low back pain. Other interventions such as health promotion, and populations including children and older people are not well represented. Further efforts to improve the quality and applicability of the evidence are warranted. 


\section{Contributors}

AC, MB and JM conceived the idea for the study. AC, HL, MB, EO, AT, SK and JM contributed to the design of the study. AC, HL, EO, AT, SK, TF, MJ and JB contributed to data collection. AC and $\mathrm{HL}$ analysed the data. AC drafted the first version of the manuscript. All authors contributed to revising the manuscript and approved of the final submitted version.

\section{Funding}

No external funding was received for this study. AC is funded by the University of New South Wales Prince of Wales Clinical School Postgraduate Research Scholarship and a NeuRA PhD Candidature Supplementary Scholarship. HL is funded by the Australian National Health and Medical Research Council (NHMRC); National Institute for Health Research (NIHR) Collaboration for Leadership in Applied Health Research and Care Oxford at Oxford Health NHS Foundation Trust. MB is funded by a NeuRA PhD Candidature Scholarship and Supplementary Scholarship and was additionally funded during this work by an Australian Government Research Training Program Scholarship and a UNSW Research Excellence Award. EO is funded by an Australian Government Research Training Program Scholarship and a NeuRA PhD Candidature Supplementary Scholarship. AT \& SK are funded by the Australian National Health and Medical Research Council (NHMRC).

\section{Ethics approval}

Ethics approval was not required for this study.

\section{Conflicts of interests}

The authors declare that they have no competing interests.

Acknowledgements: We would like to thank Associate Professor Anne Moseley from the PEDro Steering Committee for conducting the search and providing the data for this study. 


\section{REFERENCES}

[1] Hartvigsen J, Hancock MJ, Kongsted A, Louw Q, Ferreira ML, Genevay S, et al. Series Low back pain 1 What low back pain is and why we need to pay attention 2018 . doi:10.1016/S0140-6736(18)30480-X.

[2] Foster NE, Anema JR, Cherkin D, Chou R, Cohen SP, Gross DP, et al. Prevention and treatment of low back pain: evidence, challenges, and promising directions. Lancet 2018. doi:10.1016/S0140-6736(18)30489-6.

[3] Buchbinder R, van Tulder M, Öberg B, Costa LM, Woolf A, Schoene M, et al. Low back pain: a call for action. Lancet 2018;391:2384-8. doi:10.1016/S0140-6736(18)30488-4.

[4] James SL, Abate D, Abate KH, Abay SM, Abbafati C, Abbasi N, et al. Global, regional, and national incidence, prevalence, and years lived with disability for 354 diseases and injuries for 195 countries and territories, 1990-2017: a systematic analysis for the Global Burden of Disease Study 2017. Lancet 2018;392:1789-858. doi:10.1016/S0140-6736(18)32279-7.

[5] Dieleman JL, Baral R, Birger M, Bui AL, Bulchis A, Chapin A, et al. US spending on personal health care and public health, 1996-2013. JAMA - J Am Med Assoc 2016;316:2627-46. doi:10.1001/jama.2016.16885.

[6] Oliveira CB, Maher CG, Pinto RZ, Traeger AC, Lin CC, Chenot JF, et al. Clinical practice guidelines for the management of non-specific low back pain in primary care: an updated overview. Eur Spine J 2018;27:2791-803. doi:10.1007/s00586-018-5673-2.

[7] Rubinstein SM, Terwee CB, de Boer MR, van Tulder MW. Is the methodological quality of trials on spinal manipulative therapy for low-back pain improving? Int J Osteopath Med 2012;15:37-52. doi:10.1016/J.IJOSM.2012.02.001.

[8] Kamper SJ, Moseley AM, Herbert RD, Maher CG, Elkins MR, Sherrington C. 15 years of tracking physiotherapy evidence on PEDro, where are we now? Br J Sports Med 2015;49:9079. doi:10.1136/bjsports-2014-094468.

[9] Henschke N, Kuijpers T, Rubinstein SM, van Middelkoop M, Ostelo R, Verhagen A, et al. Trends over time in the size and quality of randomised controlled trials of interventions for chronic low-back pain. Eur Spine J 2012;21:375-81. doi:10.1007/s00586-011-2023-z.

[10] Koes B, Bouter L, van der Heijden G. Methodlogical quality of randomised clinical trials on treatment efficacy in low back pain. Spine (Phila Pa 1976) 1995;20:228-35. doi:10.1097/00007632-199501150-00021.

[11] Koes BW, Malmivaara A. Trend in methodological quality of randomised clinical trials in low back pain. Best Pract Res Clin Rheumatol 2005;19:529-39. doi:10.1016/J.BERH.2005.02.001.

[12] Moher D, Liberati A, Tetzlaff J, Altman DG. Preferred reporting items for systematic reviews and meta-analyses: the PRISMA statement. BMJ 2009;339:b2535-b2535.

doi:10.1136/bmj.b2535.

[13] Moseley AM, Sherrington C, Elkins MR, Herbert RD, Maher CG. Indexing of randomised controlled trials of physiotherapy interventions: a comparison of AMED, CENTRAL, CINAHL, EMBASE, Hooked on Evidence, PEDro, PsycINFO and PubMed. Physiotherapy 2009;95:151-6. doi:10.1016/j.physio.2009.01.006.

[14] Michaleff ZA, Costa LOP, Moseley AM, Maher CG, Elkins MR, Herbert RD, et al. CENTRAL, PEDro, PubMed, and EMBASE Are the Most Comprehensive Databases Indexing Randomized Controlled Trials of Physical Therapy Interventions. Phys Ther 2011;91:190-7. doi:10.2522/ptj.20100116.

[15] Sherrington C, Herbert R., Maher C., Moseley A. PEDro. A database of randomized trials and systematic reviews in physiotherapy. Man Ther 2000;5:223-6. doi:10.1054/math.2000.0372.

[16] Maher CG, Sherrington C, Herbert RD, Moseley AM, Elkins M. Reliability of the PEDro Scale for Rating Quality of Randomized Controlled Trials. Phys Ther 2003;83:713-21. doi:10.1093/ptj/83.8.713.

[17] Elkins MR, Moseley AM, Sherrington C, Herbert RD, Maher CG. Growth in the Physiotherapy Evidence Database (PEDro) and use of the PEDro scale. Br J Sports Med 2013;47:188-9. doi:10.1136/bjsports-2012-091804.

[18] Cashin AG, McAuley JH. Clinimetrics: Physiotherapy Evidence Database (PEDro) Scale. J Physiother 2019. doi:10.1016/j.jphys.2019.08.005.

[19] Jadad AR, Andrew Moore R, Carroll D, Jenkinson C, John Reynolds DM, Gavaghan DJ, et al. 
Assessing the quality of reports of randomized clinical trials: Is blinding necessary? Control Clin Trials 1996;17:1-12. doi:https://doi.org/10.1016/0197-2456(95)00134-4.

[20] Furlan AD, Malmivaara A, Chou R, Maher CG, Deyo RA, Schoene M, et al. 2015 updated method guideline for systematic reviews in the Cochrane Back and Neck Group. Spine (Phila Pa 1976) 2015;40:1660-73. doi:10.1097/BRS.0000000000001061.

[21] R Core Team. R: A language and environment for statistical computing 2013.

[22] Schulz KF, Altman DG, Moher D. CONSORT 2010 Statement: Updated guidelines for reporting parallel group randomised trials. BMC Med 2010;8:18. doi:10.1186/1741-7015-818.

[23] Boutron I, Altman DG, Moher D, Schulz KF, Ravaud P. CONSORT Statement for Randomized Trials of Nonpharmacologic Treatments: A 2017 Update and a CONSORT Extension for Nonpharmacologic Trial Abstracts. Ann Intern Med 2017;167:40. doi:10.7326/M17-0046.

[24] Moseley AM, Herbert RD, Maher CG, Sherrington C, Elkins MR. Reported quality of randomized controlled trials of physiotherapy interventions has improved over time. J Clin Epidemiol 2011;64:594-601. doi:10.1016/j.jclinepi.2010.08.009.

[25] Schulz KF. Methodological quality and bias in randomised controlled trials. London School of Hygiene \& Tropical Medicine, 1994. doi:10.17037/PUBS.04646508.

[26] Schulz F, Grimes DA, Schulz KF. Blinding in randomised trials: hiding who got what. Lancet 2002;359. doi:10.1016/S0140-6736(02)07816-9.

[27] Elkins MR, Moseley AM. Intention-to-treat analysis. J Physiother 2015;61:165-7. doi:10.1016/j.jphys.2015.05.013.

[28] Page MJ, Higgins JPT, Clayton G, Sterne JAC, Hróbjartsson A, Savović J. Empirical evidence of study design biases in randomized trials: Systematic review of meta-epidemiological studies. PLoS One 2016;11. doi:10.1371/journal.pone.0159267.

[29] Savović J, Jones H, Altman D, Harris R, Jűni P, Pildal J, et al. Influence of reported study design characteristics on intervention effect estimates from randomised controlled trials: combined analysis of meta-epidemiological studies. Health Technol Assess (Rockv) 2012;16:1-81. doi:10.3310/hta16350.

[30] Jüni P, Altman DG, Egger M. Systematic reviews in health care: Assessing the quality of controlled clinical trials. BMJ 2001;323:42-6. doi:10.1136/BMJ.323.7303.42.

[31] Schulz KF, Chalmers I, Hayes RJ, Altman DG. Empirical evidence of bias. Dimensions of methodological quality associated with estimates of treatment effects in controlled trials. JAMA 1995;273:408-12. doi:10.1001/jama.273.5.408.

[32] Schulz K, Grimes DA. Allocation concealment in randomised trials: defending against deciphering. Lancet 2002;359:614-8.

[33] Wood L, Egger M, Gluud LL, Schulz KF, Jüni P, Altman DG, et al. Empirical evidence of bias in treatment effect estimates in controlled trials with different interventions and outcomes: meta-epidemiological study. BMJ 2008;336:601-5. doi:10.1136/bmj.39465.451748.AD.

[34] Ioannidis JPA, Greenland S, Hlatky MA, Khoury MJ, Macleod MR, Moher D, et al. Increasing value and reducing waste in research design, conduct, and analysis. Lancet 2014;383:166-75. doi:10.1016/S0140-6736(13)62227-8.

[35] Yordanov Y, Dechartres A, Porcher R, Boutron I, Altman DG, Ravaud P. Avoidable waste of research related to inadequate methods in clinical trials. BMJ 2015;350:h809-h809.

doi:10.1136/bmj.h809.

[36] de Almeida MO, Saragiotto BT, Maher C, Costa LOP. Allocation Concealment and IntentionTo-Treat Analysis Do Not Influence the Treatment Effects of Physical Therapy Interventions in Low Back Pain Trials: a Meta-epidemiologic Study. Arch Phys Med Rehabil 2019;100:1359-66. doi:10.1016/j.apmr.2018.12.036.

[37] Moustgaard H, Clayton GL, Jones HE, Boutron I, Jørgensen L, Laursen DLT, et al. Impact of blinding on estimated treatment effects in randomised clinical trials: Meta-epidemiological study. BMJ 2020;368:16802. doi:10.1136/bmj.16802.

[38] Herbert RD. Meta-epidemiological studies of bias may themselves be biased. J Clin Epidemiol 2020. doi:10.1016/j.jclinepi.2020.03.024.

[39] Fregni F, Imamura M, Chien HF, Lew HL, Boggio P, Kaptchuk TJ, et al. Challenges and 
Recommendations for Placebo Controls in Randomized Trials in Physical and Rehabilitation Medicine. Am J Phys Med Rehabil 2010;89:160-72. doi:10.1097/PHM.0b013e3181bc0bbd.

[40] Boutron I, Tubach F, Giraudeau B, Ravaud P. Blinding was judged more difficult to achieve and maintain in nonpharmacologic than pharmacologic trials. J Clin Epidemiol 2004;57:54350. doi:10.1016/j.jclinepi.2003.12.010.

[41] Boutron I, Guittet L, Estellat C, Moher D, Hróbjartsson A, Ravaud P. Reporting methods of blinding in randomized trials assessing nonpharmacological treatments. PLoS Med 2007;4:0370-80. doi:10.1371/journal.pmed.0040061.

[42] Glazov G, Yelland M, Emery J. Low-dose laser acupuncture for non-specific chronic low back pain: a double-blind randomised controlled trial. Acupunct Med 2014;32:116-23. doi:10.1136/acupmed-2013-010456.

[43] Oosterhof J, De Boo TM, Oostendorp RAB, Wilder-Smith OHG, Crul BJP. Outcome of transcutaneous electrical nervestimulation in chronic pain: Short-term results of a doubleblind, randomised, placebo-controlled trial. J Headache Pain 2006;7:196-205. doi:10.1007/s10194-006-0309-z.

[44] Traeger AC, Lee H, Hübscher M, Skinner IW, Moseley GL, Nicholas MK, et al. Effect of Intensive Patient Education vs Placebo Patient Education on Outcomes in Patients With Acute Low Back Pain. JAMA Neurol 2019;76:161. doi:10.1001/jamaneurol.2018.3376.

[45] Hancock MJ, Maher CG, Latimer J, McAuley JH. Selecting an appropriate placebo for a trial of spinal manipulative therapy. Aust J Physiother 2006;52:135-8. doi:10.1016/S00049514(06)70049-6.

[46] Hancock MJ, Maher CG, Latimer J, McLachlan AJ, Cooper CW, Day RO, et al. Assessment of diclofenac or spinal manipulative therapy, or both, in addition to recommended first-line treatment for acute low back pain: a randomised controlled trial. Lancet 2007;370:1638-43. doi:10.1016/S0140-6736(07)61686-9.

[47] Costa LOP, Maher CG, Latimer J, Hodges PW, Herbert RD, Refshauge KM, et al. Motor Control Exercise for Chronic Low Back Pain: A Randomized Placebo-Controlled Trial. Phys Ther 2009;89.

[48] Gotzsche PC. Blinding during data analysis and writing of manuscripts. Control Clin Trials 1996;17:285-90. doi:10.1016/0197-2456(95)00263-4.

[49] MacCoun R, Perlmutter S. Blind analysis: Hide results to seek the truth. Nature 2015;526:187-9. doi:10.1038/526187a.

[50] Kamper SJ, Yamato TP, Williams CM. The prevalence, risk factors, prognosis and treatment for back pain in children and adolescents: An overview of systematic reviews. Best Pract Res Clin Rheumatol 2016;30:1021-36. doi:10.1016/j.berh.2017.04.003.

[51] Prince MJ, Wu F, Guo Y, Gutierrez Robledo LM, O'Donnell M, Sullivan R, et al. The burden of disease in older people and implications for health policy and practice. Lancet 2015;385:549-62. doi:10.1016/S0140-6736(14)61347-7. 